\title{
Institutions and Representational Roles in American State Legislatures
}

Christopher A. Cooper (Contact Author)

Belk 279

Department of Political Science \& Public Affairs

Western Carolina University

Cullowhee, NC 28723

(828) 227-3861

ccooper@email.wcu.edu

Lilliard E. Richardson, Jr.

105 Middlebush Hall

Truman School of Public Affairs

University of Missouri

Columbia, MO 65211

(573) 882-1947

richardsonle@missouri.edu

\section{AUTHOR INFORMATION:}

Christopher Cooper is Assistant Professor of Political Science and Public Affairs, MPA Director, and Faculty Fellow at the Institute for the Economy and the Future at Western Carolina University. His work on state legislatures, political communication and interest groups has appeared in a variety of journals, including American Politics Research, Political Research Quarterly, Social Science Quarterly, State Politics and Policy Quarterly, and State and Local Government Review.

Lilliard Richardson is Associate Professor in the Harry S Truman School of Public Affairs at the University of Missouri. His research on state politics and public policy has appeared in journals such as Legislative Studies Quarterly, Political Research Quarterly, Social Science Quarterly, State Politics and Policy Quarterly, Policy Studies Journal, and State and Local Government Review. 


\begin{abstract}
:
What is the impact of legislative institutions on the representational roles their members adopt? We address this question by examining the role orientation of state legislators in eight states, explaining why some legislators identify more with a trustee model of representation while others identify more with the delegate model. Using ordinal logistic regression analysis on data from a survey of 447 legislators, we test for the effects of multimember districts and term limits, as well as several other factors. First, we find that representational roles and behavior are related; legislators who think of themselves more as delegates are much more likely to hold frequent district office hours than their counterparts who think of themselves more as trustees. Second, we find that, overall, legislators are more likely to consider themselves trustees than delegates. Third, we find multimember districts and term limits increase the likelihood that legislators will think of themselves as trustees. Thus, legislative institutions can influence the representational roles legislators adopt.
\end{abstract}


A basic tenet of political science holds that institutions can affect behavior (Shepsle and Weingast 1995). For example, when rules in a legislative body change, we expect policies produced by the chamber to change as a result (Larimer 2005). Likewise, as rules surrounding elections change, so do the outcomes of those elections (Cox 1990). Although it is generally understood that institutions can affect representation (Moncrief, Thompson, and Cassie 1996), most research on representation has focused on one case-Congress-whose institutions have largely remained constant. ${ }^{1}$ In keeping with Jewell's $(1983,310)$ call to uncover the "variables that may help to explain particular role orientations" we leverage the institutional variation in the American state legislatures to test whether legislative institutions can influence legislators' representational roles. We also demonstrate the influence of legislator role orientations on legislative behavior and describe the distribution of representational roles among American state legislators. In doing so, we gain a better sense of how representation is practiced and how institutions shape outcomes in American state legislatures.

\section{REPRESENTATIONAL ROLES}

Scholars and practitioners of American politics have long debated the proper form of representation. We see this as far back as during deliberations over the ratification of the United States Constitution where anti-Federalists and Federalists sparred over whether legislators should make decisions they believe are in the "best interest of the state" or decisions that "follow the will of the governed" (Carman 2003, 2). More recently, scholars have placed these trade-offs on a scale characterizing role orientations from "delegate" to "trustee" (Pitkin 1967), with politicos residing somewhere in the middle (Wahlke et al. 1962). Delegates believe that they are in office to follow the unfiltered opinion of the people. A pure delegate does not feel it proper to express his or her own opinion on an issue, but rather votes based on the opinion of his or her constituents. On the other 
hand, a pure trustee believes that he or she is in office to act for his or her district making the best decision possible on some objective criteria, regardless of what the constituency may believe at that moment. When district opinion and legislator opinion about the best course of policy action come into conflict, a trustee believes that the opinion of the people is less important than the considered opinion of the legislator. Many trace the evolution of the trustee model to Edmund Burke, who argued it was advisable for representatives to "promote the interests of constituents without consulting their wishes" (Rosenthal 1998, 8).

Which of these roles are most prominent in practice in the United States? Most scholars have found that state and national legislators in this country are more likely to characterize themselves as trustees than as delegates (Cavanaugh 1982; Gross 1978; Hanson 1989; Rosenthal 1998; Wahlke, Eulau, Buchanan and Ferguson 1962). While it is instructive to think of this concept in terms of the ideal types of delegate or trustee, most legislators fall somewhere in the middle. Many legislators even display different roles on different issues. Nonetheless, legislators' general tendencies can teach us a great deal about how they view representation and the relationship between citizens and their elected officials.

While scholars have debated the usefulness of these concepts for years (Cavanaugh 1982; Gross 1978), most have found that representational roles vary in systematic and predictable ways (Carmen 2003) and that they have important implications for understanding representation. These role orientations are particularly useful in explaining legislative behavior on salient issues where constituents may have well established opinions (Kuklinski and Elling 1977; McCrone and Kuklinski 1979). For instance, Lipinski (2003) argues that the rhetoric a legislator uses about representational roles has important implications for how that legislator is viewed by the public.

Even in political systems with strong party discipline, representational roles vary and can affect behavior (Searing 1991, 1994). Studlar and McAllister (1996) showed that in Australian 
legislatures these roles affect both constituency service and vote margins, and Searing (1991) suggests these roles do a better job of explaining time spent in the district for British members of parliament than tenure, electoral marginality, party, or distance from home. Clearly, these roles affect not only a legislator's own ideas about representation, but they also affect his or her legislative behavior.

\section{EXPLAINING REPRESENTATIONAL ROLES}

Many factors may influence the representational role a legislator adopts. Because the impact of institutional characteristics are the primary focus of this article, we address them first, concentrating on two major variables: multimember districts (MMDs) and term limits.

Single-member districts, in which only one legislator is elected to represent a district, are by far the most common electoral structure in the United States today, but several American state legislatures and many legislatures worldwide use at least some multimember districtsMMDs in which more than one legislator is chosen on the same ballot to serve a single district. Most research on legislative representation has focused on single-member district systems, so the impact of this aspect of district structure on representation has rarely been examined (Bowler and Farrell 1993). Extant research is dated and anecdotal, but it generally suggests legislators who serve in multimember districts are less known to their constituents, and therefore are considered less accountable. For example, Jewell $(1982,119)$ found "legislators were more likely to be trustees in states using multimember districts, somewhat more likely to be trustees where a recent shift had been made from multimember to single-member districts, and slightly more likely to be delegates where singlemember districts had long been used." Legislators in single-member districts are better known to their constituents, and they must listen to the entire district, rather than just a small subconstituency, if they wish to be re-elected. As a result, they are "more vulnerable to pressure from groups that are 
concentrated in the district" (Jewell 1982, 119), and they must hew closer to the demands of their constituents. In other words, "single-member districts...tend to bring members and constituents closer together" (Rosenthal 1998, 29).

These differences in district structure may produce legislators with different role orientations because they create different incentives for candidates, with MMDs changing the incentive away from the focus on the median voter that single-member districts encourage (Cox 1990). For example, in a race involving four candidates running for two seats on the same ballot, one who receives less than $26 \%$ of the vote from any part of the constituency may win a seat. Further, such a race may pit two fellow party members against one another as well as against members of the opposite party. In general, a MMD candidate does not have to seek the center of the district's ideological distribution in order to win (Adams 1996; Cox 1990; Richardson, Russell and Cooper 2004). Therefore, legislators who wish to seek re-election need only concentrate on their subconstituency of active supporters, and can ignore the median voter. This leads us to our first major hypothesis:

$\mathbf{H}_{1}$ : Legislators who serve in multimember districts are more likely to claim to be trustees.

The most recent wave of institutional reform in state legislatures has been term limits. In an effort to reduce careerism in state legislatures, in the 1990s, 21 states passed laws limiting the number of terms their lawmakers can serve. While five states have since removed these limits, 29 chambers in 15 states still have limits on legislative service that range from six to 12 years. By July 2005, 1218 legislators had been termed out, but five chambers had not yet reached the date to implement their limits (National Conference of State Legislators 2005).

Both reformers and scholars expected term limits to alter the relationship between legislators and constituents. The trustee argument relies on the idea that ambitious legislators are driven by the reelection motive (Mayhew 1974), and the removal of long-term electoral pressures reduces the 
incentive to focus on constituency preferences (Glazer and Wattenburg 1996). Because term-limited legislators are not as motivated by re-election, they may spend more time engaged in lawmaking and less time on constituency casework, pork barrel projects, and other issues related to their districts (Carey, Niemi, and Powell 2000). Will (1992) argues that term limits will lead to the election of citizen legislators who will be more likely to follow their own conscience rather than hew strictly to constituency preferences. Therefore, a term-limited legislator may be more likely to act as a trustee.

Other scholars have argued against the Burkean shift toward a trustee role and presented contrary evidence. For example, Petracca (1991) argues that legislative professionalism distances legislators from their constituents, but term limits would be more likely to produce citizen legislators who would "be of the people they would represent" and "think as they think." Taking a different approach, Wright (2004) uses NOMINATE scores for all state legislative chambers in 1999-2000, and he finds "absolutely no evidence that constituency preferences matter less in chambers where term limits have been implemented" (19).

To test the effect of term limits, one could use a dummy variable for any legislator in a state with term limits. But during recent years (and our study period), many states with term limits are comprised of members who were elected before and after term limits became law. The single dummy variable approach assumes that all legislators in such a legislature when term limits were passed would change their behavior and attitudes in response to the removal of the electoral incentive. This assumption may be unwarranted. Many veteran legislators in our dataset may not have considered term limits when they were first elected, but all first-time legislators in the four states we surveyed in 2003 were recruited after term limits had removed some legislators in the state. Therefore we hypothesize two different effects of term limits on representational roles. We assess separately whether term limits affect all sitting legislators or whether the main effect is through the recruitment of legislators with different attitudes than the incumbent legislators who were replaced. 
$\mathbf{H}_{2 \mathrm{~A}}$ : All legislators subject to term limits are more likely to claim to be trustees.

$\mathbf{H}_{2 \mathrm{~B}}$ : Legislators elected for the first time under term limits are more likely to claim to be trustees.

In addition to these impacts of legislative institutions, a number of other factors may influence legislative representational roles. To make unbiased tests of our hypotheses of institutional effects, we must control for these forces in our models. First, consider that legislators are elected from very different types of constituencies even within the same state. We expect that legislators who represent heterogeneous districts are more likely to consider themselves to be trustees since they will find it more difficult to identify a single district opinion (Fiorina 1974). Districts can be heterogeneous on a variety of dimensions, but an important one in American politics is ethnic diversity. To create a state legislative district ethnic diversity variable, we collected data directly from each state's Secretary of State when available, and when not available, we used geographic information systems software to determine the percentage of each Census block group in a state in our sample (2000 summary tape 3 or SF3) that fell within each state legislative district and divided the demographic data accordingly (US Bureau of the Census 2005). We summed the demographic data for each legislative district based on the block group fragments contained within the district. The result is an estimate of the demographic profile of each legislative district. We then used Hero and Tolbert's (1996) formula to calculate a racial heterogeneity score for each district. ${ }^{2}$ Theoretically, this variable could vary from 0 to 1.0, with a district composed entirely of one ethnic category receiving the low score and one with several ethnic groups equally represented receiving the high score. In our dataset, our lowest scoring legislative district (.007) was one in South Dakota that was $99.7 \%$ white non-Hispanic, and the highest scoring district (.714) was one in New Jersey with 22.0\% Latinos, 37.0\% white non-Hispanic, 29.0\% black, and 12.0\% Asian Americans. 
Another characteristic of a legislative district that could affect a legislator's representational role is how far removed it is from the state capital. A legislator who lives far from the capital may find it more difficult to travel to the district and spend time with his or her constituents suggesting that he or she would adopt more of a trustee role because of the difficulty of determining the district's wishes.

Legislator characteristics may also be important in shaping a legislator's representational style. Because African-American legislators often represent more homogeneous majority-minority districts, black state legislators may act more like delegates than their white colleagues (Swain 1993; Whitby 1997; Burnside and Haysley-Jordan 2003). On the other hand, there is little evidence as to this effect for other minority legislators. While the states included in our study were served by black, Latino/a, Native-American, and Asian-American legislators, in addition to white legislators, there were too few survey respondents in some ethnic categories to create separate variables for each. Therefore, we include a single ethnic minority variable in our models to control for any effect, based on the legislator's self-identified minority status.

Freshman legislators may enter the legislature with different ideas about representation than they have later in their careers. Specifically, because of electoral uncertainty and traditional homestyle patterns, we would expect that first-time legislators are more likely to consider themselves to be delegates. Lipinski (2003) finds some evidence supporting this hypothesis in the congressional context, but no work explicitly examines this relationship in the state legislature.

There is also some reason to believe that women legislators view their job differently than their male colleagues. Differences in sex-role socialization may lead women to spend more time in their districts and to conduct more constituency service than men (Carey, Niemi, and Powell 1998; Richardson and Freeman 1995). As a result, we expect that female legislators are more likely to perceive themselves as delegates than their male counterparts. 
Finally, the strength of a legislator's ideology may affect his or her role orientation. Legislators who consider themselves to be extreme liberals or extreme conservatives are likely to hold strong worldviews on a range of policies, and therefore, they may feel less compelled to look to anyone else in their legislative activities, even their constituents (Richardson, Russell and Cooper 2004). If so, then these ideological extremists are more likely to consider themselves to be trustees than their more moderate colleagues.

Thus, theory and previous research suggests a number of potential predictors of representational roles. Specifically, we expect that all else being equal, multimember districts and term limits encourage legislators to perceive themselves as trustees, and ideological extremists will also be more inclined to self-identify as trustees. On the other hand, we expect that legislators who are members of ethnic minorities, in their first term, female, or represent homogenous districts are more likely to view themselves as delegates.

\section{DATA AND METHODS}

To test these hypotheses, we gathered data using an original mail survey of state legislators in eight states: Arizona, Colorado, Missouri, New Jersey, North Dakota, Pennsylvania, South Carolina, and South Dakota. This survey was sent to 1176 legislators in June 2003. After three weeks, we sent a second wave to nonrespondents. A third wave was sent to nonrespondents in states with particularly low response rates. The survey procedures conformed to Dillman's Tailored Design Method (2000). ${ }^{3}$

Overall, the survey had a $42 \%$ response rate, with each state having a response rate of at least $32 \%(\mathrm{AZ}=53 \%, \mathrm{CO}=48 \%, \mathrm{MO}=48 \%, \mathrm{NJ}=32 \%, \mathrm{ND}=47 \%, \mathrm{PA}=34 \%, \mathrm{SC}=35 \%, \mathrm{SD}=52 \%)$. To account for different response rates in the states, we "weighted the sample by a factor proportional to the inverse of the overall probability of selection and of response," following Carey, 
Niemi, and Powell's $(2000,688)$ approach in their 50-state survey of state legislators. The response rate compares favorably with that of other surveys of state legislatures (e.g. Maestas 2003) and other elite samples (e.g. Abbe and Herrnson 2004).

Furthermore, our nonrespondents do not seem to have biased our sample in any obvious way, because the demographic characteristics of the sample are similar to the population of legislators in these eight states in 2003. For example, the survey sample includes 19\% female legislators (compared to $18 \%$ in the population of these eight state legislatures), $36 \%$ are who first time legislators (compared to $31 \%$ in the population), and 54\% Republicans (compared to 54\% in the population.

We chose these states for the survey sample for several reasons. First, half of these states (AZ, NJ, SD, ND) have MMDs in their lower chambers and single-member districts (SMD) in their upper chambers. The district lines in these states are identical for both chambers, providing an ideal place to investigate the effects of district structure on representation. These are the only four states in the country with such a structure. There are a number of types of MMDs (Cox 1990), but we focus on the classic bloc MMD system in these four states. ${ }^{4}$ In this form, a MMD occurs when two or more legislators are elected from the same geographic area at the same time. In these four states the ballot may include a number of candidates (from two to seven in the 2002 election), and voters are instructed to vote for no more than two. The other four states $(\mathrm{CO}, \mathrm{MO}, \mathrm{PA}, \mathrm{SC})$ in the sample have SMD lower and upper chambers.

Second, half of these states (AZ, CO, MO, and SD) have implemented term limits, and the other half have not. Each of these states has an eight-year limit, but only Missouri precludes termed out legislators from running again after sitting out an election. The National Conference of State Legislators (2005) estimates that 235 legislators had been termed out in these eight states by 2003 when the survey was administered. Third, the sampled states display wide variation on state 
legislative professionalism. For example, ND and SD are citizen legislatures, while PA and NJ are among the most professional in the nation. The remainder are hybrid states, residing somewhere between the two extremes (Kousser 2005). Finally, the states also vary considerably in terms of political culture (Elazar 1966) and policy liberalism (Gray et al. 2004). Overall, these eight states provide us with a representative cross-section of American state legislatures. Detailed information about these states is presented in Table 1.

[Table 1 About Here]

Although the states vary along these five dimensions (multimember legislative districts, legislative term limits, legislative professionalism, political culture, and liberalism), we did not test the impact of each of them on legislative representational roles. Our primary interest is in the effects of institutions on these roles, so we include MMDs and term limits as independent variables in our model explaining variation in role orientations, but we do not include political culture or liberalism. Including these variables would introduce too many state-level variables in the model, providing unique identifiers that are virtually perfectly collinear. Culture is most problematic because it is closely related to professionalism in our sample, with both of our citizen legislatures labeled as moralistic and both our professional legislatures described as individualistic. Furthermore, Hero and Tolbert (1996) demonstrate that ethnic diversity (which we include in the model) is highly correlated with culture nationwide.

Legislative professionalism (Mooney 1994) is difficult to include in our model because it also relates very closely with MMD status in our sample, with the majority of our MMD respondents being from states with low professionalism scores. Despite this practical difficulty, this is a variable that speaks closely to our original research question. Professionalism is an institutional arrangement that could affect a legislator's role orientation by affecting his or her insulation from his or her constituents, thus affecting how free he or she can be to act as a trustee (Berry, Berkman, 
Schneiderman 2000). In addition, the staff and other resources available in professional legislatures may help legislators in these districts keep in better touch with district opinion, which would facilitate a delegate style of representation (Maestas 2003). To account for the effect of legislative professionalism but to avoid the extreme collinearity problem identified above, we use professionalism as the cluster variable in the robust standard error estimates in our models rather than as an independent variable (Wooldridge 2003; Franzese 2005). This specification avoids the extreme collinearity problem but allows the impact of professionalism to be accounted for in the model by adjusting the standard errors for intragroup correlation within the three broad professionalism categories of citizen, hybrid, and professional legislatures (Kousser 2005, 14-16).

\section{RESULTS}

In this section, we describe the distribution of legislators on a scale of representational roles. Next, we test whether self-professed representational role orientations affect legislative behavior. After all, if these roles do not influence any behavior, there is little reason to describe or explain their variation. Once we establish a behavioral link, we present a series of multivariate models that explain variation in these roles.

\section{The Distribution of Representational Roles}

First, consider the distribution of legislators on a 7-point representational role scale ranging from delegate (1) to trustee (7), presented in Figure 1. This figure demonstrates two important points for our analysis. First, there is considerable variation on these self-reported roles. Some legislators consider themselves pure trustees, a few consider themselves pure delegates, and the majority consider themselves to be something in between. Second, the scale is heavily skewed toward the trustee orientation. Clearly, legislators tend to weigh their opinion of the best interest of 
the district heavily when making decisions. This is consistent with previous studies in the state legislature (Cavanaugh 1982; Gross 1978; Hanson 1989; Rosenthal 1998) and it may reflect either a normative bias towards claiming to be decisive and principled or simply the lack of knowledge that most citizens have about what the state legislature does most of the time.

[Figure 1 About Here]

\section{The Behavioral Implications of Representational Roles}

To assess the behavioral implications of representational role orientation we estimated a model where the dependent variable represents the frequency with which a legislator holds office hours in his or her district (ranging from very infrequently to daily). The frequency of office hours is an important behavioral indicator of how much importance a legislator places on casework, and presumably how seriously a legislator takes the opinions of his or her constituents (Freeman and Richardson 1994). Our key independent variable indicates where the legislator falls on the delegatetrustee scale. We also include a number of control variables to account for alternative explanations for the frequency of office hours that have been found to affect commitment to constituents in other areas. These variables are district homogeneity (Fenno 1978), whether the legislator is a minority (Haynie 2001), the distance from the district to the capital (Munger and Hart 1989), whether the legislator is a female (Richardson and Freeman 1995), whether the legislator is an ideological extremist (Richardson, Russell, and Cooper 2004), and whether the legislator is a freshman (Hibbing 1991). We expect that delegates are more likely to hold frequent office hours than their colleagues who fall toward the trustee end of the scale. ${ }^{5}$

[Table 2 About Here]

The estimated model in Table 2 clearly supports our hypothesis. The more a legislator identifies with the trustee role, the less frequently a legislator reported district office hours $(\mathrm{p}<.01)$, indicating that trustees are less connected to their districts. To determine the strength of this 
relationship, we estimated the predicted probabilities for the extremes of the role orientation scale (see Table 3). Holding all other variables at their sample means or modes, we estimate that a pure trustee has a $42 \%$ chance of holding daily or weekly office hours, while a pure delegate has almost a $66 \%$ chance. Alternatively, we estimate trustees to have a $53 \%$ chance of only monthly or infrequently holding office hours, whereas a delegate has less than a $30 \%$ probability of such infrequent constituent contact. While most legislators are not located on either extreme of this scale, these results indicate that role orientation and behavior are strongly related. Delegates act differently toward their constituents than trustees; representational roles and legislative behavior are related.

[Table 3 About Here]

\section{Explaining Variation in Representational Roles}

Next, we attempt to explain the variation in representational roles among legislators, focusing primarily on the hypotheses of institutional effects related to MMDs and term limits. Our dependent variable represents responses to our survey question about legislative role orientation, ranging from 1 (pure delegate) to 7 (pure trustee). This dependent variable is negatively skewed, which is problematic for ordinary least squares regression. Furthermore, legislators filling out the survey could rank the categories in the scale, but we may not be able to assume equal distances between the categories, again raising concerns for OLS analysis of these data (McKelvey and Zavoina 1975; Long and Freese 2001). Consequently, we use ordinal logistic regression, which is appropriate for this sort of dependent variable, along with robust standard errors with clustering on the legislative professionalism categories of citizen, hybrid and professional (Kousser 2005) to account for clustering in the data (Wooldridge 2003; Franzese 2005).

Our primary hypotheses are that legislators representing MMDs and legislators in a termlimits state (especially first-time legislators in term-limit states, operationalized with an interaction 
between freshman status and being in a term limited state) will be more likely to self-identify as a trustee (choosing one of the higher scores on our 7-point scale). We also expect legislators representing more homogenous districts, those who live farther from the state capital, ideological moderates, freshmen, female and ethnic minority legislators to be more likely to be delegates. In Table 4, we test these hypotheses using ordinal logistic regression analysis. Overall, our results strongly suggest that there is a systematic component to a legislator's choice of representational role. The effects of the variables for MMD, freshman in a term-limited state, distance from the capital, and freshman, female and minority legislator are all statistically significant.

[Table 4 About Here]

Consider first our primary hypotheses of institutional effects. The MMD variable's estimated coefficient is positive and statistically significant, suggesting that legislators who are elected from MMDs are more likely to self-identify as trustees than legislators who are elected from SMDs, who are more likely to consider themselves to be delegates. Given that MMDs seem to promote a trustee version of legislative representation, it is possible that at least some of the decline in representative democracy in legislatures that Rosenthal (1998) observes is due to the decline of multimember districts in the past few decades.

Beyond simply confirming our hypothesis, this finding indicates that more research needs to be done on the effects of district structure on styles of legislative representation. Much has been written on the influence of MMDs on descriptive representation (Arceneaux 2001; Hogan 2001; King 2002; Moncrief and Thompson 1992) and ideological extremity (Adams 1996; Cox 1990; Richardson, Russell, and Cooper 2004), but few studies have considered how district structure influences interactions with constituents, and the influence of those interactions on legislator decision-making. Given that millions of Americans reside in multimember state legislative districts, this is clearly an important subject that deserves more study. 
The term limits variable main effect is not statistically significant so we must reject Hypothesis 2A. Term limits do not appear to affect all legislators the same way. On the other hand, the interaction effect between freshman and term limits is significant, supporting Hypothesis $2 \mathrm{~B}$, indicating that legislators who are elected knowing that they will serve under term limits are more likely to consider themselves trustees. Note that the estimated coefficient for the freshman main effect variable is negative and statistically significant. This suggests that freshmen in non-term limited legislatures enter the office with very different ideas about representation than legislators in term-limited legislatures. The effect of being a freshman in a non-term limited state is to incline one towards being a delegate, but this effect is virtually negated in term limit states. Although term limits were created to bring legislators closer to their constituents, the positive significant coefficient on the freshman-term limits interaction variable shows that term limits actually negate the pull toward being a delegate that freshman tend to feel. Because these freshman legislators no longer can consider a long-term career in their chamber, they are more able to pursue their own policy goals rather than the goals of the district. This finding should give pause to term limits reformers who see the reform as enhancing representation, and it speaks to recent scholarly debates over the representational effects of term limits (Carey et al. 2003; Wright 2004).

The model in Table 4 also has several control variables with statistically significant effects. Those legislators who live farther from the state capital are less likely to be trustees. Perhaps legislators who live farther from the capital must make more of an effort to connect with their constituents because they spend less time at home. Because they are less able to provide the symbolic representation of spending time in their district, they may react by acting more as delegates for their constituents.

These results also suggest female legislators are more likely to consider themselves to be delegates. This is consistent with previous studies suggesting that female legislators pay more 
attention to district concerns (Richardson and Freeman 1995; Carey, Niemi, and Powell 1998), but it contradicts previous studies that suggest female legislators are less inclined to see themselves as delegates than male legislators (Reingold 2000).

Likewise, minority legislators are significantly more likely to consider themselves to be delegates. This result is consistent with Swain (1993), Whitby (1997), and Burnside and HaysleyJordan (2003), but it stands in stark contrast to the Lipinski (2003) study that finds minority legislators tend to be trustees. Because previous research focused mainly on African Americanlegislators, we also ran this model with just a dichotomous variable for black legislators. The estimated coefficient was quite similar (-.302), and it was also statistically significant. Furthermore, because of the possibility of collinearity with the district diversity measure, we tested the model without the district measure and found much the same results for black legislator or minority legislator. Finally, we tested for an interaction between the district diversity measure and minority variable, and it was not significant. These results suggest that our findings are quite robust to alternate specifications. Clearly, the role orientation of minority legislators is an area that deserves further exploration.

\section{CONCLUSION}

The study of political representation has a long and productive history in political science. Recently, scholars of Congress (Lipinski 2003), public opinion (Carman 2003), state legislatures (Rosenthal 1998; Smith 2003), and comparative politics (Searing 1991, 1994; Studlar and McAllister 1996; Taylor 1992) have used the concept of representational roles to gain a better understanding of how legislators and their constituents relate to one another. Our study of representational roles in the state legislature addressed three questions: 1) Are self-reported representational roles related to behavior, 2) where do legislators place themselves on a scale of representational roles, and 3) how do 
institutions affect the type of representational roles legislators? In particular, we are interested mainly in the effects of multimember districts and term limits on these roles.

Our study has produced three notable findings. First, self-identified representational roles and legislative behavior are related. Legislators who claim to be closer to the delegate end of the scale are much more likely to hold frequent office hours than legislators who are more likely to identify themselves as trustees. This supports recent comparative research that demonstrates the importance of representational roles for understanding legislative behavior (Searing 1991; Studlar and McAllister 1996).

Second, we find that legislators tend to prefer a trustee model of representation, one that follows that advocated by Edmund Burke more than 200 years ago (Burke 1967). This, of course, is not terribly surprising. Since Wahlke et al.'s (1962) early study of state legislatures, most scholars have found that legislators claim to prefer this style of representation. Thus, despite the "decline in representative democracy" (Rosenthal 1998) and myriad changes in American politics, role orientations do not appear to have changed much over the past 40 years.

Third, and most important, we find that representational roles have a systematic component, and this is in large part driven by institutional arrangements. First-time legislators who were elected after the implementation of term limits and those who represent multimember districts are significantly more likely to consider themselves to be trustees. Representational roles are also influenced by certain demographic factors. Legislators who represent districts farther from the state capital, freshman legislators in non-term-limited states, female legislators, and legislators who are members of ethnic minorities are more likely to consider themselves to be delegates.

The effects of institutional structure on representational roles should be of special interest to political scientists and reformers alike because these structures reflect public policy choices, and, as such, they can be changed through the political process. Scholars have learned much about the 
influence of district structure on descriptive representation, but few have examined how this can affect the relationship between legislators and their constituents. Jewell (1982) believed that singlemember district systems produced legislators who were more responsive to their districst, both in terms of their role orientation and their attitudes toward casework. Our study surveying more than 400 state legislators finds support for Jewell's hypothesis. In addition, legislators in two of our MMD states, North Dakota and South Dakota, represent small, homogeneous districts, districts that previous work has shown tend to produce legislators who describe themselves as delegates (Fenno 1978; Rosenthal 1981; Squire 1993). We believe this gives our findings further credibility. If, MMDs generate trustees even in these sort of districts, the institutional influence here must be strong, indeed.

Term limits is another institutional feature that we find produces systematic effects on representation. While term limits were enacted for a variety of reasons (Carey, Niemi and Powell 2000; Kousser 2005), an important argument of their advocates was that these limits would take careerism out of state politics and bring legislators closer to the people. Our evidence suggests that they may have a different effect. Because term-limited legislators face considerably reduced electoral incentives, they may be more likely to eschew a delegate style of representation and make decisions based on their own views. In other words, term limits could produce legislators who fall closer to the Burkean ideal of trustee. While more time is needed for the effects of term limits to be assessed fully, our finding that freshmen legislators elected under term limits tend toward being trustees gives support for this hypothesis. Finally, reformers who seek to eliminate multimember districts in the states and who seek to enact term limits should find much that is useful in this analysis. 


\begin{tabular}{|c|c|c|c|}
\hline \multicolumn{4}{|c|}{ Appendix 1: Source and Coding of Variables } \\
\hline Variable Name & Question Wording or Source & Range & Mean/Mode \\
\hline Representational Role & $\begin{array}{l}\text { "As you think about your job as state legislator, where would you place } \\
\text { yourself on a scale of delegate to trustee where delegate represents a } \\
\text { legislator who votes strictly on the preferences of the voters, and trustee } \\
\text { represents a legislator who uses their own best judgment to decide } \\
\text { issues?" }\end{array}$ & $1-7$ & 5.04 \\
\hline Legislative professionalism & From King 2000 & $.102-.403$ & .256 \\
\hline MMD & Coded by authors & $0-1$ & 0 \\
\hline Term limits & Coded by authors & $0-1$ & 0 \\
\hline Ethnic diversity & Calculated from 2000 Census data, as per Hero and Tolbert 1996. & $.007-.714$ & .253 \\
\hline Ideological extremist & $\begin{array}{l}\text { "How would you describe your political views on a scale of } 1-7 \text { where } \\
1=\text { extremely liberal and } 7=\text { extremely conservative?" } \\
\text { This was recoded as the absolute value of this score minus } 4 \text { so that } \\
\text { moderates equal } 0 \text { and extremists equal } 3 \text {. }\end{array}$ & $0-3$ & 1.31 \\
\hline Female legislator & Coded by authors from online bios of legislators. & $0-1$ & 0 \\
\hline Freshman legislator & Coded by authors from online bios of legislators. & $0-1$ & 0 \\
\hline Freshman $\mathrm{x}$ term limits & Interaction term & $0-1$ & 0 \\
\hline Minority legislator & $\begin{array}{l}\text { "How would you classify your ethnicity? Caucasian, Latino/Latina, } \\
\text { African American, Native American, Asian American, Other." } \\
\text { This was recoded as Minority (non-Caucasian) }=1 \text {; Caucasian }=0\end{array}$ & $0-1$ & 0 \\
\hline Office hours & $\begin{array}{l}\text { "How often do you personally hold office hours for the public in your } \\
\text { district? } 5=\text { daily; } 4=\text { =weekly; } 3=\text { every two weeks; } 2=\text { monthly; } \\
1=\text { infrequently." }\end{array}$ & $1-5$ & 2.70 \\
\hline District distance from capital & $\begin{array}{l}\text { Calculated by entering the legislator's hometown into Mapquest and } \\
\text { mapping the distance to the state capital. }\end{array}$ & $0-420$ & 124.6 \\
\hline
\end{tabular}

Note: Variables defined by question wording are from the authors' June 2003 survey of state legislators in eight states. 


\section{Endnotes}

${ }^{1}$ For a good review of what we know (and what we don't) about representation in the state legislature, see Moncrief, Thompson and Cassie (1996).

${ }^{2}$ Hero and Tolbert's (1996) formula is: diversity $=1-\left((\% \text { Latino })^{2}+(\% \text { Black })^{2}+(\% \text { White })^{2}+\right.$ $\left.(\% \text { Asian })^{2}+(\text { American Indian })^{2}+(\text { Other })^{2}\right)$. The actual groups used for this calculation varied by state depending on data availability, and the numbers for all groups other than Latino were for nonHispanics.

${ }^{3}$ A complete description of the survey instrument is available at http://paws.wcu.edu/ccooper.

${ }^{4}$ For instance, in some states (such as New Hampshire), there are more than two seats in some districts. Other varieties include seat, staggered, and cumulative MMDs. Seat MMDs occur when there are two openings on a ballot in a single-district, but candidates must specify for which of the seats they are running and voters then choose among different slates of candidates for seat $\mathrm{A}$ and seat B. Washington and Idaho use seat MMDs. Staggered MMDs occur when two or more legislators represent the same geographic area in the same chamber but are elected in different years. The United States Senate has staggered MMDs (Schiller 1996). Various districting arrangements are often referred to by the common name MMD, but they can have very different electoral effects (Hamm and Moncrief 1999). As a result, in our article, we refer to the classic bloc form of MMD rather than any of its variants.

${ }^{5}$ Text of the questions can be found in the Appendix. 


\section{REFERENCES}

Abbe, Owen G., and Paul S. Herrnson. 2003. "Campaign Professionalism in State Legislative Elections." State Politics and Policy Quarterly 3: 223-45.

Adams, Greg D. 1996. "Legislative Effects of Single-Member vs. Multi-Member Districts." American Journal of Political Science 40: 129-44.

Arceneaux, Kevin. 2001. “The Gender Gap in State Legislative Representation: New Data to Tackle an Old Question.” Political Research Quarterly 54: 143-60.

Berry, William D., Michael B. Berkman, and Stuart Schneiderman. 2000. "Legislative Professionalism and Incumbent Reelection: The Development of Institutional Boundaries.” American Political Science Review 94: 859-74.

Bowler, Shaun, and David M. Farrell. 1993. "Legislator Shirking and Voter Monitoring: Impacts of European Parliament Electoral Systems upon Legislator-Voter Relationships.” Journal of Common Market Studies 31: 45-69.

Burke, Edmund. 1967. "Our Conscience is a Trust from Providence.” In The Represented, edited by Neal Riemer. Boston: D.C. Heath.

Burnside, Randolph, and Virginia Haysley-Jordan. 2003. “The Roles of Representation Among Black State Legislators: An Analysis of Welfare Reform.” Presented at the Annual Meeting of the Midwest Political Science Association, Chicago, IL.

Carey, John M., Gary F. Moncrief, Richard G. Niemi, and Lynda W. Powell. 2003. "Term Limits in the State Legislature: Results from a New Survey of the 50 States.” Presented at the Annual Meeting of the American Political Science Association, Philadelphia, PA.

Carey, John M., Richard Niemi, and Lynda Powell. 1998. "Are Women State Legislators Different?" In Women and Elective Office: Past, Present, and Future, eds. Sue Thomas and Clyde Wilcox. New York: Oxford University Press. 
Carey, John M., Richard G. Niemi, and Lynda W. Powell. 2000. Term Limits in the State Legislatures. Ann Arbor, MI: The University of Michigan Press.

Carman, Christopher Jan. 2003. "Public Preferences for Political Representation." Presented at the Annual Meeting of the Midwest Political Science Association, Chicago, IL.

Cavanagh, Thomas E. 1982. “The Calculus of Representation: A Congressional Perspective.” Western Political Quarterly 35: 120-29.

Cox, Gary W. 1990. “Centripetal and Centrifugal Incentives in Electoral Systems.” American Journal of Political Science 34: 903-35.

Dillman, Don A. 2000. Mail and Internet Surveys: The Tailored Design Method. New York: John Wiley.

Elazar, Daniel J. 1966. American Federalism: A View from the States. New York: Thomas Y. Crowell.

Fenno, Richard F, Jr. 1978. Home Style: House Members in Their Districts. Boston, MA: Little Brown.

Fiorina, Morris. 1974. Representatives, Roll Calls, and Constituencies. Lexington, MA: D.C. Heath.

Franzese, Robert J. 2005. "Empirical Strategies for Various Manifestations of Multilevel Data," Political Analysis 13: 430-446.

Freeman, Patricia K., and Lilliard E. Richardson. 1994. "Casework in State Legislatures." State and Local Government Review 26: 21-6.

Gray, Virginia, David Lowery, Matthew Fellowes, and Andrea McAtee. 2004. "Public Opinion, Public Policy, and Organized Interests in the American States.” Political Research Quarterly 57: $411-20$.

Gross, Donald A. 1978. "Representational Styles and Legislative Behavior." Western Political Quarterly 31: 359-371.

Hamm, Keith E., and Gary F. Moncrief. 1999. "Legislative Politics in the States.” In Politics in the American States: A Comparative Analysis, eds. Virginia Gray, Russell L. Hanson, and Herbert Jacob. $7^{\text {th }}$ ed. Washington DC: CQ Press. 
Hanson, Royce. 1989. Tribune of the People. Minneapolis, MN: University of Minnesota Press.

Haynie, Kerry L. 2001. African American Legislators in the American States. New York: Columbia University Press.

Hero, Rodney E., and Caroline J. Tolbert. 1996. "A Racial/Ethnic Diversity Interpretation of Politics and Policy in the States of the U.S." American Journal of Political Science 40: 851-71.

Hibbing, John R. 1991. Congressional Contours of Life in the U.S. House of Representatives. Chapel Hill, NC: University of North Carolina Press.

Jewell, Malcolm E. 1969. Metropolitan Representation: State Legislative Districting in Urban Counties. New York: National Municipal League.

Jewell, Malcolm E. 1982. Representation in State Legislatures. Lexington, KY: University Press of Kentucky.

Jewell, Malcolm E. 1983. "Legislator-Constituency Relations and the Representative Process." Legislative Studies Quarterly 8: 303-37.

King, Gary, Michael Tomz, and Jason Wittenberg. 2000. "Making the Most of Statistical Analyses: Improving Interpretation and Presentation.” American Journal of Political Science 44: 347-61.

King, James D. 2002. "Single Member Districts and the Representation of Women in American State Legislatures: The Effects of Electoral System Change.” State Politics and Policy Quarterly 2: 161-75.

Kousser, Thad. 2005. Term Limits and the Dismantling of State Legislative Professionalism. New York: Cambridge University Press.

Kuklinski, James H., and Richard C. Elling. 1977. "Representational Role, Constituency Opinion, and Legislative Roll-Call Behavior.” American Journal of Political Science 21: 135-47.

Larimer, Christopher W. 2005. “The Impact of Multimember State Legislative Districts on Welfare Policy." State Politics and Policy Quarterly 5: 265-82. 
Lipinski, Daniel. 2003. "Rhetoric on Representation: Which Members of Congress Portray Themselves as Delegates?” Presented at the Annual Meeting of the Southern Political Science Association, Savannah, GA.

Long, J. Scott, and Jeremy Freese. 2001. Regression Models for Categorical Dependent Variables Using Stata. College Station, TX: Stata Press.

Maestas, Cherie. 2003. "The Incentive to Listen: Progressive Ambition, Resources, and Opinion Monitoring among State Legislators." Journal of Politics 65: 439-56.

McCrone, Donald J., and James H. Kuklinski. 1979. “The Delegate Theory of Representation.” American Journal of Political Science 23: 278-300

McKelvey, Richard D., and William Zavonia. 1975. "A Statistical Model for the Analysis of Ordinal Level Dependent Variables.” Journal of Mathematical Sociology 4: 103-120.

Moncrief, Gary F., and Joel A. Thompson. 1992. "Electoral Structure and State Legislative Representation: A Research Note." Journal of Politics 54: 246-56.

Moncrief, Gary, Joel Thompson, and William Cassie. 1996. "Revisiting the State of State Legislative Research.” Legislative Studies Quarterly 21:301-35.

Mooney, Christopher Z. 1994. "State Legislative Professionalism: An Evaluation of Five Indices." State and Local Government Review 26:70-8.

Munger, Michael C., and Douglas Hart. 1989. "Declining Electoral Competitiveness in the House of Representatives: the Differential Impact of Improved Transportation Technology." Public Choice 61: 217-31.

National Conference of State Legislatures. 2005. "The Term Limited States." Available at: <http://www.ncsl.org/programs/legman/about/states.htm>.

Petracca, Mark P. 1991. “The Poison of Professional Politics.” Policy Analysis no 151. Available at $<$ Cato.org $>$ 
Pitkin, Hannah F. 1967. The Concept of Representation. Berkeley, CA: University of California Press.

Reingold, Beth. 2000. Representing Women: Sex, Gender, and Legislative Behavior in Arizona and California. Chapel Hill, NC: University of North Carolina Press.

Richardson, Lilliard E., Jr., and Patricia K. Freeman. 1995. "Gender Differences in Constituency Service among State Legislators.” Political Research Quarterly 48: 169-179.

Richardson, Lilliard E., Jr., Brian E. Russell, and Christopher A. Cooper. 2004. "Legislative Representation in a Single-Member versus Multiple-Member District System: The Arizona State Legislature.” Political Research Quarterly 57: 337-44.

Rosenthal, Alan. 1981. Legislative Life: People, Process, and Performance in the States. New York: Harper \& Row.

Rosenthal, Alan. 1998. The Decline of Representative Democracy: Process, Participation, and Power in State Legislatures. Washington, DC: CQ Press.

Schiller, Wendy J. 2000. Partners and Rivals: Representation in U.S. Senate Delegations. Princeton, NJ: Princeton University Press.

Searing, Donald D. 1994. Westminster's World: Understanding Political Roles. Cambridge, MA: Harvard University Press.

Smith, Michael A. 2003. Bringing Representation Home: State Legislators Among Their Constituencies. Columbia, MO: University of Missouri Press.

Shepsle, Kenneth A., and Barry Weingast, eds. 1995. Positive Theories of Congressional Institutions. Ann Arbor, MI: University of Michigan Press.

Squire, Peverill. 1993. "Professionalization and Public Opinion of State Legislators." Journal of Politics 55: 479-491.

Studlar, Donley T., and Ian McAllister. 1996. "Constituency Activity and Representational Roles among Australian Legislators." Journal of Politics 58: 69-90. 
Swain, Carol. 1993. Black Faces, Black Interests. Cambridge, MA: Harvard University Press.

Taylor, Michelle M. 1992. "Formal versus Informal Incentives Structures and Legislator Behavior: Evidence from Costa Rica." Journal of Politics 54: 1055-73.

Tomz, Michael, Jason Wittenberg, and Gary King. 2003. CLARIFY: Software for Interpreting and Presenting Statistical Results. Version 2.1. Stanford University, University of Wisconsin, and Harvard University. January 5. Available at <http://gking.harvard.edu $>$.

US Bureau of the Census. 2005. Census 2000 Summary File 3 (SF 3) - Sample Data. Available at: <ftp://ftp2.census.gov/census_2000/datasets/Summary_File_3/>.

Wahlke, John C., Heinz Eulau, William Buchanan and LeRoy C. Ferguson. 1962. The Legislative System: Explorations in Legislative Behavior. New York: John Wiley.

Whitby, Kenny J. 1997. The Color of Representation. Ann Arbor: University of Michigan Press.

Wooldridge, Jeffrey M. 2003. "Cluster-Sample Methods in Applied Econometrics." American Economic Review 93: 133-138.

Wright, Gerald C. 2004. "Do Term Limits Limit Representation?” Presented at the Fourth Annual Conference on State Politics and Policy, Kent State University. 
Table 1. Characteristics of the Sample States

\begin{tabular}{lccccc}
\hline & Professionalism & MMD $^{\mathbf{2}}$ & $\begin{array}{c}\text { Term } \\
\text { Limits }^{\mathbf{3}}\end{array}$ & $\begin{array}{c}\text { Dominant } \\
\text { Culture }^{\mathbf{4}}\end{array}$ & \begin{tabular}{c} 
Policy $_{\text {Liberalism }^{\mathbf{5}}}$ \\
\hline Arizona
\end{tabular} \\
Colorado & .279 & Yes & Yes/2000 & Traditional & 32 \\
Missouri & .273 & No & Yes/1998 & Moralistic & 19 \\
New Jersey & .295 & No & Yes/2002 & Individualistic & 21 \\
North Dakota & .369 & Yes & No & Individualistic & 14 \\
Pennsylvania & .102 & Yes & No & Moralistic & 46 \\
South Carolina & .403 & No & No & Individualistic & 25 \\
South Dakota & .208 & No & No & Traditional & 20 \\
\hline
\end{tabular}

${ }^{1}$ Source: King 2000

${ }^{2}$ MMD states have MMDs in the lower house, but no MMDs in the upper chamber.

${ }^{3}$ Source: NCSL 2004. "Yes" denotes that a state has legislative term limits, with the year of full implementation shown for those states (from NCSL 2004)

${ }^{4}$ Source: Elazar (1966)

${ }^{5}$ Source: Gray, et al. 2004. Lower numbers indicate a more liberal state. 
Table 2. Model Predicting Frequency of Office Hours

\begin{tabular}{lc}
\hline Variable & $\begin{array}{c}\text { Estimated Coefficient } \\
\text { (Std. Error) }\end{array}$ \\
\hline Representational Role & $-0.172 * * *$ \\
Ethnic diversity & $(0.060)$ \\
& 0.574 \\
Minority legislator & $(1.473)$ \\
District distance from capital (in 100s) & 0.453 \\
& $(0.382)$ \\
Female legislator & -0.087 \\
Ideological extremist & $(0.202)$ \\
Freshman legislator & $-0.625^{* * *}$ \\
& $(0.124)$ \\
N & $-0.203^{* *}$ \\
Log pseudo-likelihood & $(0.080)$ \\
\hline
\end{tabular}

Estimation technique: Ordinal logistic regression with robust standard errors, adjusted for clustering on legislative professionalism.

Note: We do not report the intercepts for the different levels of the ordinal dependent variable.

$* * * \mathrm{p}<.01$

$* * \mathrm{p}<.05$

$*_{\mathrm{p}}<.10$, all tests are two-tailed 
Table 3: Predicted Probabilities of the Frequency of District Office Hours for Different Representational Roles

\begin{tabular}{lcc}
\hline & $\begin{array}{c}\text { Probability of holding office hours } \\
\text { monthly or infrequently }\end{array}$ & $\begin{array}{c}\text { Probability of holding office hours } \\
\text { daily or weekly. }\end{array}$ \\
\hline Delegate & .297 & .659 \\
Trustee & .528 & .421 \\
\hline
\end{tabular}

Note: These estimates were produced using CLARIFY (King, Tomz, and Wittenberg 2000; Tomz, Wittenberg and King 1999) from the estimated model in Table 2, holding all other variables at their sample means or modes. 


\begin{tabular}{lc}
\hline Table 4: Model Predicting Legislators' Representational Roles \\
\hline Variable & $\begin{array}{c}\text { Estimated Coefficient } \\
\text { (Std. Error) }\end{array}$ \\
\hline Multimember District & $0.168^{* * *}$ \\
Term Limits & $(0.038)$ \\
Term Limits X Freshman & 0.181 \\
& $(0.244)$ \\
District Ethnic Diversity & $0.722^{* * *}$ \\
Miles from Capital (in Hundreds) & $(0.041)$ \\
Ideological Extremist & -0.133 \\
& $(0.835)$ \\
Freshman Legislator & $-0.167^{* *}$ \\
Female Legislator & $(0.082)$ \\
Minority Legislator & 0.292 \\
& $(0.208)$ \\
N & $-0.980^{* * *}$ \\
Log pseudo-likelihood & $(0.117)$ \\
\hline
\end{tabular}

Estimation technique: Ordinal logistic regression with robust standard errors, adjusted for clustering on legislative professionalism.

Note: We do not report the intercepts for the different levels of the ordinal dependent variable.

$* * * \mathrm{p}<.01$

${ }^{* *} \mathrm{p}<.05$

${ }^{*} \mathrm{p}<.10$, all tests are two-tailed 
Figure 1. Representational Roles in State Legislatures

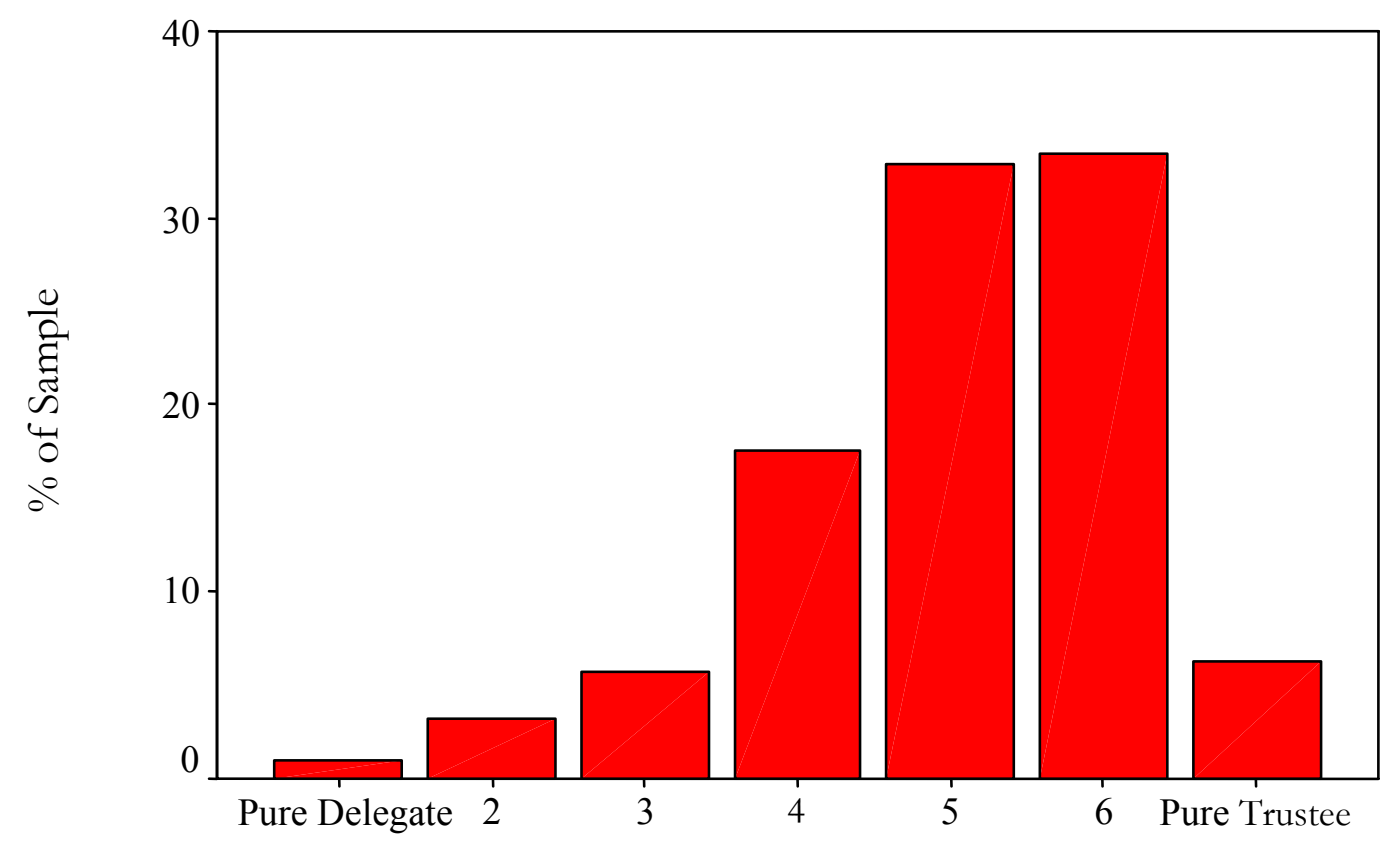

Source: Authors' Survey

$\mathrm{N}=434$

Note: This figure shows the percentage of our sample of 434 state legislators in eight states who placed themselves on each point in our seven-point representational role scale. 